
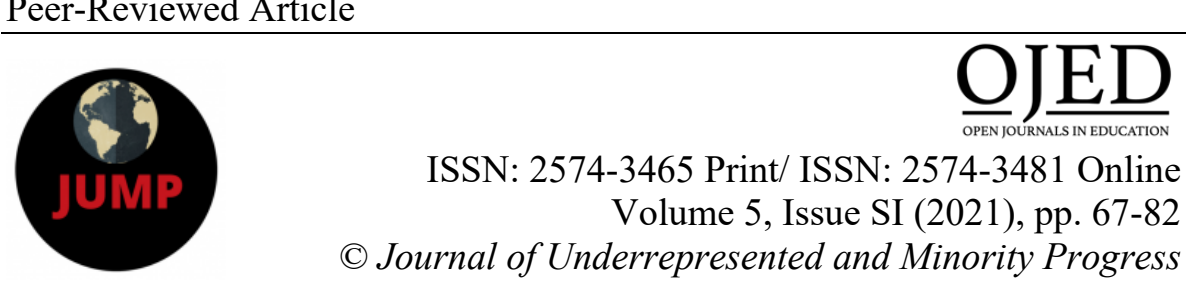

ISSN: 2574-3465 Print/ ISSN: 2574-3481 Online Volume 5, Issue SI (2021), pp. 67-82

(C) Journal of Underrepresented and Minority Progress http://ojed.org/jump

\title{
Empathizing with Black Women's Experiences at the Intersections of Collective Trauma, Isolation, Anxiety, Depression, and HIV/AIDS amid a Global Pandemic: Narratives of Two Community Based Organization (CBO) Service Providers
}

\author{
Mattyna L. Stephens \\ Texas A\&M University, USA \\ Gwenetta Curry \\ University of Edinburgh, UK \\ Stacey Stephens \\ University of Maryland, USA
}

\begin{abstract}
The novel coronavirus (COVID-19) emerged in the United States toward the close of 2019. CBOs were forced to either change their hours of operation or completely close their doors to avoid further widespread dissemination of the virus. The abrupt changes among CBOs posed some challenges for people living with HIV/AIDS (PLWHA), especially Black women living with HIVIAIDS (BWLHA). For this reason, this study aimed to explore the impact of the global pandemic on BWLHA receiving services from $C B O$ service providers. A qualitative inquiry was used to examine the narratives of two CBOs' service providers (i.e., Narrators 1 and 2). Hill-Collins's (1990) Black Feminist Theory was utilized to frame the research. Three approaches to narrative analysis also were employed to analyze participants' stories. Such narratives helped to underscore the trauma experienced by BWLHA. The stories also reflected feelings of loneliness, anxiety, and depression among the women. Meditation and advocacy were forms of learning provided for the women. The participation in "sister circles" was recognized as a system of support. Implications for practice suggested that CBOs' service providers develop collective trauma care plans that are comprehensive, specific to client's needs, and informed by adult learning principles to help BWLHA navigate trauma events.
\end{abstract}

Keywords: anxiety, care plans, BWLHA, CBOs, collective trauma, depression, pandemic. 


\section{INTRODUCTION}

While working through the needs of individuals affected by HIV/AIDS related issues, service providers were confronted with an unexpected pandemic. The novel coronavirus (COVID-19) emerged in the United States in 2019. Moreover, COVID-19 claimed the lives of over 200,000 Americans within a matter of months (Cooper et al., 2020). Because of the potency and unpredictability of the virus, the pandemic is believed to be the most cataclysmic in modern day history (Haleem \& Javaid, 2020). In response to the uncertainty of the virus and its transmission, people were asked to shelter in place. Over time, the number of such orders increased (Hsiang et al., 2020; Pinto \& Park, 2020). In response, CBOs were forced to either change their hours of operation or completely close their doors to avoid further widespread dissemination of the virus. The abrupt changes among CBOs posed some challenges for people living with HIV/AIDS (PLWHA), especially BWLHA. Since Black women have the leading cases of HIV/AIDS in the United States, it was essential to focus our attention on this populace of women.

The effect of stigma on Black women's treatment and care has been well documented in the literature (Sangaramoorthy et al., 2017; Whiteside et al., 2014). There is also a significant amount of literature on Black women's risk for HIV/AIDS (Davis \& Tucker-Brown, 2013). However, there is a limited amount of literature on the impact of the COVID-19 pandemic on BWLHA and how the virus disrupted services for this populace of women. There is also a limited amount of literature on CBOs' support (e.g., treatment and care) efforts for BWLHA during the pandemic. We designed this research to fill these gaps through sharing the narratives of two service providers at two different CBOs who provided services to BWLHA. Therefore, the purpose of this study was to explore the impact of the global pandemic on BWLHA receiving services from CBOs. The following research questions guided the study:

1. How has the pandemic disrupted CBOs' HIV/AIDS efforts (e.g., treatment and care) for BWLHA?

2. How has the global pandemic affected the health and well-being of BWLHA?

3. What strategies and resources do CBO service providers offer to BWLHA to strengthen and protect their health during a global pandemic?

This article is organized as follows: (a) centering Black women's experiences, (b) a literature review, (c) research methods, (d) personal narratives, (e) findings and discussion, (f) conclusion, and (g) implications. 


\section{Centering Black Women's Experiences}

For this research, Black Feminist Theory (BFT) was used to center the women's experiences at the intersections of Black, female, poverty, ageism (Hill-Collins, 1990), and HIV/AIDS from the perspectives of CBO service providers. A tenet within BFT is that Black women's experiences cannot exist separately from their intersectionalities (Hill-Collins, 1990, p. 5). Acknowledging these intersectionalities helped us to understand the experiences of BWLHA amidst a global pandemic. However, according to Barritau (2006), some argue that there is no need for BFT because of the homogeneous impression of global sisterhood and the idea that feminist agendas are adequate for framing Black women's experiences. To challenge these ideologies, several authors have argued feminist frameworks are not sufficient to effectively explore the realities of Black women (Barritau, 2006; Carter-Francique, 2013; Opara, 2017). Moreover, feminist theories have suppressed Black women's ideologies. As such, we used BFT to centralize the experiences of BWLHA as told through the narratives of service providers at CBOs who work closely with BWLHA.

\section{LITERATURE REVIEW}

The literature selected from multiple databases informed the development of the literature review. This literature review is organized as follows: (a) Black women's risk or HIV/AIDS, (b) Black women living with HIV, and (c) CBOs.

\section{Black Women's Risk for HIV/AIDS}

In the literature, Nydegger et al. (2020) named violence as a primary factor in women's increased risk for HIV/AIDS. Violence can be viewed as occurring at multiple levels, including structural (Nydegger et al., 2020) and intimate partner violence (Gilbert et al., 2000; Weaver et al., 2015). Intimate partner violence can include acts of forced or coerced sex with an HIVinfected partner (Kouyoumdjian et al., 2013). Kouyoumdjian and colleagues (2013) conducted a systematic literature review and found a correlation between intimate partner violence and HIV risk among Black women. Poverty, gender inequality, racism, and homelessness can be categorized as structural violence (Nydegger et al., 2020; Riley et al., 2007). For Black women living in poverty, the promotion of education or behavior change may be insufficient for HIV prevention, as Black women's lives often intersect with exploitation, marginalization, powerlessness, and violence. Davis and Tucker-Brown (2013) identified sexual oppression, sexualized images, poverty, racial segregation, and incarceration as social determinant factors that place Black women at risk for HIV/AIDS. Davis and Tucker-Brown (2013) further indicated the persistence of social inequalities dating as far back as slavery have always placed Black women at a disadvantage, making 
it difficult for them to create a life filled with economic security. Moreover, ongoing economic deprivation and other social determinant factors have contributed to the prevalence of HIV/AIDS among Black women.

\section{Black Women Living With HIV/AIDS}

In the United States, one in 54 Black women is living with HIV compared to one in 941 White women (Kaiser Family Foundation, 2019). African Americans constitute only 13\% of the U.S. population, yet Black women represent $65 \%$ of the women living with HIV in the United States (Fletcher et al., 2016). BWLHA have unique and specific health needs (i.e., microsystem, exosystem, and macrosystem; El-Bassel et al., 2009) though they are often left out of the conversations on HIV/AIDS related issues (Black Women's Health Imperative, 2019; Rao et al., 2018). Individuals tend to associate HIV/AIDS with homosexuality despite its increased prevalence among Black heterosexual women, further marginalizing BWLHA.

There is a consensus that as of 2017, Black women accounted for $59 \%$ of the newly diagnosed cases of HIV in the United States (CDC, 2018; Geter et al., 2019), whereas White and Latino women accounted for only $20 \%$ and $16 \%$, respectively. Findings from a qualitative study revealed, without negating other documented adversities, stigmatization has the greatest impact on BWLHA (Fletcher et al., 2016). Some authors have described stigma as occurring at multiple levels, including interpersonal, community, and institutional (Fletcher et al., 2016; Sangaramoorthy et al., 2017). Interpersonal stigma is associated with experiences within one's direct social environment; community stigma intersects interpersonal relationships and the wider community; and institutional stigma is operationalized in larger structures such as regulatory institutions, including healthcare systems, reformatories, and the workplace (Fletcher et al., 2016). Black women's lack of engagement in treatment and care is largely the result of HIV associated stigma, which leads to reduced care and treatment, preventive behavior of poor quality, negligent behavior toward care and retention, poorer medical and psychological care, negligent behavior toward testing, diminished feelings toward status disclosure, and reduced uptake of pre-exposure prophylaxis (PrEP) (Fletcher et al., 2016; Whiteside et al., 2014). The deleterious effects of stigmatization among BWLHA beckon the attention of leaders of CBOs for prevention, advocacy education, and care (Operario et al., 2020).

\section{Community-Based Organizations}

To offer a comprehensive approach to care, some CBOs employ a workforce comprising social workers, case managers, navigators, and health educators to help BWLHA access testing, medical professionals for PrEP, or other medicinal supports, including primary care for those women who may test positive for HIV, and support services for at-risk women who have the 
propensity to fall out of the care continuum (Black Women's Health Imperative, 2019). Gailbraith (1995) indicated members of the CBOs' workforce serve in the role of adult educator to the clients they serve by providing formal, nonformal, and informal learning across the lifespan.

According to Wilson and colleagues (2012), advocacy is a key function of CBOs. When the work of advocacy is operationalized, CBOs can better support the systems of care in which they are associated. Since its emergence, COVID-19 has posed many challenges for CBOs that offer services to people living with HIV/AIDS (PLWHA; Operario et al., 2020; Pinto \& Park, 2020). For example, the virus has brought about a noticeable reduction in resources offered by CBOs. A temporary suspension of services is not an option as many $\mathrm{CBOs}$ rely heavily upon program revenues.

Leaders of many CBOs that offer socializing opportunities have been advised to halt non-essential programming because of the pandemic, making social isolation much more challenging for PLWHA (Marziali et al., 2020; Operario et al., 2020). PLWHA sometimes experience poverty, which makes it difficult for them to remain in contact with family members and friends because they lack access to cell phones, internet services, computers, and other technologies during this time of physical distancing (Chenneville et al., 2020, p. 2). Moreover, increased bouts with depression because of the COVID-19 mandates have caused setbacks for many clients, derailing existing efforts on the part of both the clients and the healthcare providers toward clients remaining on the care continuum (Chenneville et al., 2020, p. 2).

As the novel coronavirus continues to affect how clients engage in services, we offer narratives to begin conversations around the phenomenon to explore how the COVID-19 virus has derailed the efforts for BWLHA. As well, we explore the health and well-being of BWLHA, and the strategies and resources offered to these women during the pandemic. This research also serves as our way of placing a call to action for further exploration of the phenomenon.

\section{RESEARCH METHODS}

We employed qualitative methods in this study because they illuminate and place emphasis on individuals' contextualized experiences and give meaning to social and psychological experiences (Denzin \& Lincoln, 1994). Moreover, qualitative research is appropriate for holistically capturing Black women's experiences (Lani et al., 2014). We used the purposeful sampling technique to select participants who "can purposefully inform an understanding of the research problem and central phenomenon of the study" (Creswell, 2007, p. 125). We selected the two participants because they were workers of CBOs, they provided HIV/AIDS related services to

BLWHA, and they had been employed with their agency for at least 2 years. 


\section{Participants}

To recruit participants, we sent a message to an HIV Syndicate listserv and provided a brief description of the research to elicit interest. When potential participants responded, we followed up with an email and provided information about the study and those who were willing to participate were asked to return an email with the following statement - return of email is an agreement to participate in the study. Then, we collected demographic information. Afterward, we scheduled a mutually agreed upon time for each participant to share their narrative. Only two participants were chosen for this study to help inform a larger study. One participant identified as male and the other participant identified as female, and both participants were African American. Narrator 1 had served in the role of health educator for over 20 years and Narrator 2 had served in the role of case manager for almost 5 years.

We wanted to share their narratives to help call attention to the myriad challenges BWLHA are facing amid the novel coronavirus and to offer some insight to service providers at CBOs who work with this population. Notably, the quotes are interpretations of the women's experiences as expressed by the participants. Engagement with the participants was conducted over the phone and the participants did not engage in a typical interview process, as we used storytelling as a form of data collection. According to Brookfield (2013), storytelling can help individuals make sense of their personal experiences and reveal to others life's moments they find to be most compelling. We asked the participants to share stories based on the following questions: How has the pandemic disrupted CBOs' HIV/AIDS efforts for BWLHA, how has the global pandemic affected the health and well-being of BWLHA, and what strategies and resources do CBO service providers offer to BWLHA to strengthen and protect their health during a global pandemic? The participants offered short stories and we compiled them into complete narratives (DeMedeiros \& Etter-Lewis, 2020).

We analyzed the narratives using three approaches. First, we applied Alexander's (1988) approach to narrative analysis as we read the narratives multiple times and used principles of salience to focus on word meaning, rather than the specifics of language. While Alexander introduces nine principles, four were significant to the analysis process. Such principles included frequency, omission, incompletion, and emphasis, to make meaning of the participants' stories. Then, we used elements of Denzin's (1989) life narrative to identify important events and verbalized insights or epiphanies within the participants' narratives. Denzin further noted such elements occur in most stories. A third method we used in our narrative analysis was a linguistic approach that was culturally specific. Because the participants were African American, there was an assumption that they would provide insights outside of the "dominant culture." Therefore, we used culture (Johnson- 
Bailey, 2002) as the narrative analysis tool to give meaning to service providers' stories. The focus in our cultural analysis was on the manners in which Black people communicate, repetition of words and phrases, emphasis placed on words, and the use of Black English. Offering three methods for analysis helped us to fully explore the participants' experiences. To check for trustworthiness, participants were given the opportunity to review their narratives to help contextualize their experiences (Goings, 2016).

\section{PERSONAL NARRATIVES}

To protect the identities of the participants, they are identified as Narrator 1 and Narrator 2. Their stories are delineated in the following paragraphs.

\section{Narrative 1: Health Educator}

At the beginning of the interview, Narrator 1 explained, "Justice and equity are not established for Black women many times. There is also structural inequity within the healthcare system making it difficult for Black women to receive the proper care and treatment." As a health educator, Narrator 1 provided services such as health education, counseling, health literacy (e.g., uptake of PrEP and other anti-retroviral therapy), food bank services, and other support to BWLHA at a CBO.

Narrator 1 stated when the novel coronavirus emerged, it completely disrupted the care and treatment she provided for clients. The shelter in place orders served to separate "the agency" from the clients, as the women were no longer able to come to the center and receive services. For those women living in isolation, the lack of interaction with service providers and with other women living with the diagnosis negatively affected their mental health. Narrator 1 reported that during a webinar, one woman indicated, "I am 39 years old, but I feel like I am 90. I have a heart issue, cholesterol, and high blood pressure. I cannot take it any longer. I am going nuts." Narrator 1 also recalled instances of clients contemplating suicide because they could not stand the isolation. In such instances, Narrator 1 immediately contacted the suicide hotline so a qualified person could offer some assistance.

During the pandemic, the clients interacted with agency members, case managers, and other agency professionals through different virtual platforms (e.g., Zoom). Clients were also forced to interact with healthcare providers through telehealth systems. Many of the Black women with whom Narrator 1 worked felt that they had been cheated out of care and treatment. They felt telehealth was another way for healthcare providers to disregard their need for adequate care. BLWHA have multiple health concerns and many of the women questioned the validity of the doctors' diagnoses because of their inability to see them face-to-face. Narrator 1 stated one client indicated, "Medical professionals are working from home. If you are working 
from home, you are not dealing with me." Narrator 1 reported another client stated,

You call me so the hospital can charge my Medicare, but what did you really do for me? What did you really accomplish with me? You did not get to put me on a scale. You did not get anything effective going on.

Narrator 1 indicated another client said, "There should be check-in calls, like a wellness check just to see if we are doing okay. With everything going on [COVID-19], we could be dead in our home." Narrator 1 reported yet another client explained,

My primary care doctor-I expect them to look at the whole of me.

The pandemic started in March. I need some labs done; not just for HIV/AIDS. Labs can tell a lot about a person's health. I have 11 different doctors that I see.

The mandates for COVID-19 called for the agency to deny walk-in clients, which affected the women's ability to acquire their medications. Narrator 1 stated one client commented, "They [agency] are not taking walkins. I have not been able to take my meds for about 8 or 9 days." Narrator 1 made a call to the program manager and advocated on behalf of the client to ensure that she received her medication. Occasionally, Narrator 1 would allow clients to listen to those calls to develop skills for advocacy. Clients listened to the questions asked, how the questions were framed, and the tone of voice used. Narrator 1 stated, "Developing skills for advocacy is important. See, when women can stand up for themselves, it gets people's attention. It also builds self-confidence because many Black women living with HIV/AIDS have developed learned helplessness."

Because clients were forced to remain inside, their normal engagement in activities for learning had been replaced with television. Narrator 1 indicated,

I told them [women] sitting in front the television is not doing anything for you. You need to keep your brain functioning ... reading and learning. There are all sorts of materials ... webinars ... listening sessions ... support groups for Black women.

Narrator 1 encouraged clients to engage in online learning activities, including workshops, panel discussions, and webinars. She also suggested the women engage in reading materials online or reach out to "sister circles" or networking systems that provide up-to-date information on HIV/AIDS and other information.

\section{Narrative 2: Case Manager}

Narrator 2 served in the role of case manager within his organization. As a case manager, Narrator 2 assessed clients' wellness, developed care plans, provided counseling and intervention, charted referrals, and conducted 
home visits. Because of the pandemic, in-house HIV testing was no longer offered. At the request of the clients, the tests were mailed to their homes and they were responsible for returning the specimen by mail or dropping it off at the agency.

Prior to the pandemic, case managers often visited clients at their homes, which provided clients the opportunity to speak with case managers privately. The women relied heavily upon these interactions. In adherence to the mandates instituted in response to COVID-19, the agency was forced to discontinue home visits and case management transitioned to telehealth. For most of the clients, lack of interaction and the inability to socialize brought about feelings of loneliness.

Although some of the women shared their living spaces with other family members, they still experienced feelings of isolation, as their roommates were often unaware of their HIV/AIDS status. Therefore, they distanced themselves within their homes to prevent their family members from developing any suspicions about their diagnosis. Hiding while in isolation became emotionally labor intensive for the women, thereby increasing their anxiety. Narrator 2 stated one client explained,

I live with my cousins. They do not know that I am HIV positive. I try not to be around them too much. It is crazy. I must think about my health and at the same time try to stay away from them.

Narrator 2 stated another client indicated, "Some of my family members live with me. They say that I am too private. I cannot tell them I am HIV positive. They will tell everybody. So, I distance myself from them."

In addition, the women's weekly support group meetings were canceled. Those clients who attended the meetings, along with the facilitator, offered the psychological support the women needed to help manage their personal life experiences while living with HIV/AIDS. For instance, a client called the center, seemingly in a state of depression. Narrator 2 immediately contacted the group facilitator, who managed to get in contact with other group members and they all met through a virtual platform. The group members provided the support the distressed client needed to help counter feelings of depression and anxiety. A meeting with Black women she identified as her "sisters" was motivating. Narrator 2 indicated the client called the following day and stated, "Thank you for connecting me with the group. To hear their voices and to see their faces gave me the opportunity to get some human interaction that I am not getting." The feelings of loneliness had been exceedingly difficult for some of the women to manage. The women looked forward to the weekly face-to-face support group meetings. Such meetings provided a safe space for them to be vulnerable and allowed them the time to interact with women who looked like them and shared similar experiences. 
The persistent lack of interaction began to weigh heavily on some of the women such that they considered reverting to their old habits. Narrator 2 stated one client indicated, "I am so stressed out. Not being able to speak to people face-to-face makes me want to go back to drinking and smoking." The added pressure of being isolated with someone who was problematic caused them to consider reverting to their previous addictions. For example, Narrator 2 stated one client indicated, "My daughter mistreats me. I just feel like drinking. It gets really hard for me sometimes." Narrator 2 stated another client indicated, "The arguing back and forth is driving me crazy. If I say blue, he says green. Everything does not have to be an argument. It is enough to make you wanna have a drink."

To help the women temper their feelings of loneliness, Narrator 2 recommended meditation. Though Narrator 2 admitted to having a lack of expertise in meditation, it provided an outlet for him while adhering to the shelter in place mandates. Because employees at the agency were unable to meet with clients face-to-face, Narrator 2 mailed the women copies of activities for meditation and provided websites that offered activities for meditative purposes. Some of the women found the activities to be helpful. Narrator 2 stated one client indicated, "It takes some real concentration, but the activities kind of relax your body." Narrator 2 indicated another client stated, "It gives me something to do. Meditation takes my mind off the world. I am glad you gave us this information, Mr. Kenney [pseudonym]. These activities would be great for the women's group." The client was hinting at the idea of Narrator 2 performing activities for meditation during a virtual meeting.

\section{FINDINGS AND DISCUSSION}

Informed by the BFT, we placed the experiences of BWLHA at the center of the research through its empathetic lens. The research indicates that service providers at CBOs made Black women a focal point. Here, the women's experiences intersect racism, sexism, collective trauma, isolation, anxiety, depression, and HIV/AIDS.

In response to the pandemic, clients were ordered to shelter in place, forcing CBOs to alter the way in which they provided services to the women. Seemingly overnight, the women were separated from their CBOs. Suddenly, the women were unable to have physical contact with CBO providers, healthcare providers, or members of their support groups. Home visits with caseworkers were suspended indefinitely. Some of the women lived with roommates and faced the possibility of their diagnosis being revealed. Other women experienced maltreatment from their roommates. Some clients even considered reverting to addictions. Morin (2020) indicated pandemics can be characterized as traumatic events. Leonard (2020) indicated prolonged exposure to stressful events can be traumatizing. Morin (2020) further noted when traumatic events affect members of an entire group, in this case 
BWLHA being serviced by CBOs, the experience can be identified as collective trauma. BWLHA face existing stressors associated with HIV/AIDS, including structural violence and intimate partner violence (Nydegger et al., 2020), that make their experiences associated with the pandemic even more traumatizing. However, Morin (2020) warned that though an entire group may be affected by trauma, the burden of trauma looks different for everyone.

The shelter in place mandates led to social isolation, which triggered feelings of loneliness, anxiety, and depression among the women. Black women are more likely to experience depression because of the intersections of poverty, racism, sexism, social health difficulties, and cultural socialization practices (Martin et al., 2013). Social isolation was an added layer. In the findings, the case manager recommended the women engage in meditation practices to manage their emotions. To help ameliorate their anxiety and depression, some women engaged in activities for meditation. According to Lapina (2018), meditative activities trigger the body's response to relaxation. For adults, learning how to manage stressful circumstances is critical as it influences how they respond to daily life events, life aspects, and learning outcomes (Lapina, 2018, p. 132,). Meditation is a useful technique for achieving a clear mind as well as managing emotions. When clients' emotions were stabilized, they were better able to engage in treatment and care. As well, when clients' emotions were managed properly, they were better prepared to engage in activities for skill development. As well, the women were either advised to engage in "sister circles" or other informal support groups. Women are called to offer psychological support for other women (Nanton, 2009, p. 13). Such psychological support may include social support, anxiety reduction, and the relief of tension (Nanton, 2009, pp. 18-20). Alfred (2009, p. 7) indicated such groups can also serve as networking systems for the transaction of knowledge for upward mobility.

Some of the women felt their health concerns were not being taken seriously because they were given a diagnosis through telehealth without a thorough assessment. Acquiring anti-retroviral therapy medication was also challenging. These findings aligned with the study conducted by Onos (2020), which indicated that often the health issues of Black women are either not taken seriously or are ignored. Narrator 1 allowed clients to listen to phone conversations during which she challenged certain structures to teach clients how to self-advocate for needed services. Such training aligned with the findings of Wilson et al. (2012), which indicated advocacy is a quintessential component of CBOs. Brookfield (2013) stated challenging the structures that control information and fighting for resources that are beneficial are the indicators of women being self-directed. Moreover, when women can advocate for themselves through self-directed learning processes, it can build confidence and self-efficacy. 


\section{CONCLUSIONS}

There continues to be an increased prevalence of HIV/AIDS among Black women. BWLHA have experienced a compilation of traumatic events. A global pandemic can intensify the impact of these experiences. While there may be collective trauma among the subgroup members, the effect is different for each Black woman living with HIV/AIDS. Therefore, CBO service providers need to consider collective trauma care plans that are comprehensive (e.g., addressing physical, cognitive, and emotional health), specific to the client's needs (e.g., sister circles, advocacy, meditation), and informed by adult learning principles (e.g., transformational learning, selfdirected learning, and experiential learning) to help BWLHA navigate trauma events.

\section{IMPLICATIONS}

There are some implications of the results of this study. This study serves to widen the lens of educators of adult and higher education. Gailbraith (1995) held the view that service providers at CBOs are considered adult educators. Using an interdisciplinary approach, service providers at CBOs can offer informal learning programming to develop Collective Trauma Care Plans (CTCPs) for BWLHA. During the times of crisis, CTCPs can help women think more clearly, maintain balance, and serve as a framework for everyone involved including the women, spouses/partners, friends, or colleagues to support one another (Moss, 2020). It is important that the plan is comprehensive to meet the client's needs holistically rather than a one-sizefits-all approach. Strategies for adult development and learning differ significantly from traditional learning. Therefore, it is essential for the plan to be informed by adult learning principles (e.g., transformational learning, selfdirected learning, experiential learning, or project-based learning) to help BWLHA navigate inequitable systems during times of trauma (e.g., mass shootings, war, famines, and pandemics). Marchi (2020) indicated that when developing a CTCP, there are some elements to consider, including (a) risk factors (e.g., personal, work, cultural, etc.), (b) personal symptoms of trauma (e.g., cognitive, emotional, behavioral, etc.), (c) personal coping strategies, and (d) finding hope and meaningful work within the trauma (Moss, 2020). It is important to clearly define the objectives so the women can understand the purpose of the care plan. CBO service providers can begin a CTCP by doing the following: (a) allow the women to choose two items regarding (c) and (d) (from the above strategies), (b) allow the women to identify two actions that are measurable and realistic, (c) allow the women to develop at least two sentences they can use as a reference to manage how they respond to trauma, (d) have the women identify specific barriers that may prevent them from adhering to their plan for addressing traumatic experiences, and (e) allow the women to identify strategies to overcome such obstacles and identify systems of support (Marchi, 2020). Examples can be useful as adult learners, including 
BWLHA, can become familiar with aspects of the plans that are specific to their needs and experiences. Moreover, as clients' experiences and needs change throughout the lifespan, CBOs can be the mechanism for instigating lifelong learning opportunities for treatment and care plans among BWLHA if cultivated properly.

As with any research, there are some limitations. A limitation of the study is the actual voices of BWLHA were not included. As well, further studies with larger cohorts of service providers at other CBOs would enhance generalizability. Despite its limitations, the research illustrates how CBOs can support BWLHA during a pandemic. Future research may focus on collective trauma responses through CTCPs and their impact on the professional development of service providers at CBOs.

\section{REFERENCES}

Alexander, I. E. (1988). Personality, psychological assessment, and psychobiography. In D. P. McAdams \& R. L. Ochberg (Eds.), Psychobiography and life narratives (pp. 265-294). Duke University Press.

Alfred, M. V. (2009). Social capital theory: Implications for women's networking and learning. New Directions for Adult and Continuing Education, 122, $3-$ 12. https://doi.org/10.1002/ace.329

Barritau, V. E. (2006). "The relevance of Black feminist scholarship: A Caribbean perspective." Feminist Africa 7 Diaspora Voices (pp. 9-31). African Gender Institute.

Black Women's Health Imperative. (2019). Policy agenda for Black women. https://bwhi.org/2019/12/06/the-black-womens-health-imperative-unveilsfirst-of-its-kind-policy-agenda-addressing-hiv-aids-epidemic-among-blackwomen/

Brookfield, S. (2013). Powerful techniques for teaching adults. Jossey-Bass.

Carter-Francique, A. (2013). Black female collegiate athlete experiences in a culturally relevant leadership program. The National Journal of Urban Education and Practice, 7(2), 87-106.

Centers for Disease Control and Prevention. (2018). Preexposure prophylaxis for the prevention of HIV infection in the United States-2017 update: A clinical practice guideline. https://www.cdc.gov/hiv/pdf/risk/prep/cdc-hiv-prepguidelines-2017.pdf

Chenneville, T., Gabbidon, K., Hanson, P., \& Holyfield, C. (2020). The impact of COVID-19 on HIV treatment and research: A call to action. International Journal of Environmental Research and Public Health, 17(12), 4548. https://doi.org/10.3390/ijerph17124548

Cooper, T. J., Woodward, B. L., Alom, S., \& Harky, A. (2020). Coronavirus disease 2019 (COVID-19). Outcomes in HIV/AIDS patients: A systematic review. HIV Medicine, 21(9), 576-577. https://pubmed.ncbi.nlm.nih.gov/32671970/

Creswell, J. W. (2007). Qualitative inquiry \& research design: Choosing among five approaches. Sage Publications. 
Davis, S. K., \& Tucker-Brown, A. (2013). The effects of social determinants on Black women's HIV risk: HIV is bigger than biology. Journal of Black Studies, 44(3), 273-289. https://doi.org/10.1177/0021934713481805

De Medeiros, K., \& Etter-Lewis, G. (2020). "Place" in the small stories of African American elders: A narrative case study. Gerontologist, 60(5), 821-830.

Denzin, N. K. (1989). Interpretive biography. Sage Publications.

Denzin, N. K., \& Lincoln, Y. S. (1994). Handbook of qualitative research. Sage.

El-Bassel, N., Calderia, N. A., Ruglass, L. M., \& Gilbert, L. (2009). Addressing the unique needs of African American women in HIV prevention. American Journal of Public Health, 99(6), 996-1001. https://doi.org/10.2105/AJPH.2008.140541

Fletcher, F., Ingram, A. I., Kerr, J., Buchberg, M., Bogdan-Lovis, L., \& PhilpottJones, S. (2016). "She told them, oh that bitch got AIDS": Experiences of multilevel HIV/AIDS-related stigma among African American women living with HIV/AIDS in the South. AIDS Patient Care and STDs, 30(7), 349-356. https://doi.org/10.1089/apc.2016.0026

Gailbraith, M. (1995). Community-based organizations, and the delivery of lifelong learning opportunities (ED385253). https://files.eric.ed.gov/fulltext/ED385253.pdf

Geter, A., Sutton, M. Y., \& McCree, H. D. (2019). Social and structural determinants of HIV treatment and care among Black women living with HIV infection: A systematic review: 2005-2006. AIDS Care, 30(4), 409-416. https://doi.org/10.1080/09540121.2018.1426827

Gilbert, L., El-Bassel, N., Schilling, R., \& Wada, T. (2000). Partner violence and sexual HIV risk behaviors among women in methadone treatment. AIDS and Behavior, 4(3), 261-269. https://doi.org/10.1023/A:1009568718804

Goings, R. (2016). Investigating the experiences of two high-achieving Black male HBU graduates: An exploratory study. Negro Education Review, 67(1-4), 54-75.

Haleem, A., \& Javaid, M. (2020). Effects of COVID-19 in daily life. Current Medicine Research and Practice, 10(2), 78-79. https://www.ncbi.nlm.nih.gov/pmc/articles/PMC7147210/pdf/main.pdf

Hill-Collins, P. (1990). Black feminist thought: Knowledge, consciousness, and the politics of empowerment. Routledge.

Hsiang, S., Allen, D., Annan-Phan, S., Bell, K., Bollinger, I., Chong, T., Druckenmiller, H., Huang, L. Y., Hultgren, A., Krasovich, E., Lau, P., Lee, J., Rolf, E., Tseng, J., \& Wu, T. (2020). The effects of large-scale anticontagion policies on the COVID-19 pandemic. Nature. https://doi.org/10.1038/s41586-020-2404-8

Johnson-Bailey, J. (2002). Dancing between the swords: My foray into constructing narratives. In S. B. Merriam \& Associates (Eds.), Qualitative research in practice: Examples for discussion and analysis (pp. 323-326). Jossey-Bass.

Kaiser Family Foundation. (2019). The HIV/AIDS epidemic in the United States: The basics. https://www.kff.org/hivaids/fact-sheet/the-hivaids-epidemic-in-theunited-states-the-basics/

Kouyoumdjian, F. G., Findlay, N., Schwandt, M., \& Calzavara, L. M. (2013). A systematic review of the relationships between intimate partner violence and 
HIV/AIDS. PLos $\quad$ One, $\quad$ 1-25.

https://doi.org/10.1371/journal.pone.0081044

Lani, V. J., Hopson, L., Warner, L., Hardiman, E. R., \& James, T. (2014). A qualitative study of Black women's experiences in drug abuse and mental health services. Journal of Women and Social Work, 30(1), 68-82.

Lapina, A. (2018). Facilitating coping through reflective learning in adult education. Adult Learning Journal, 29(4), 131-140. https://doi.org/10.1177/1045159518776126

Leonard, J. (2020, June 3). What is trauma? What to know. https://www.medicalnewstoday.com/articles/trauma

Marchi, M. (2020). Making a trauma-informed self-care plan. The Pennsylvania Child Welfare Resource Center. http:/www.pacwrc.pitt.edu/Curriculum/313 MngngImpctTrmtcStrssChld WlfrPrfssnl/hndts/HO06 MkngTrmInfrmdSlfCrPln.pdf

Martin, A., Boadi, N., Fernandes, C., Wyatt, S., \& Robinson-Wood, T. (2013). Applying resistance theory to depression in Black women. Journal of Systemic Therapies, 32(1), 1-13. https://doi.org/10.1521/jsyt.2013.32.1.1

Marziali, M. E., Card, K. G., McLinden, T., Wang, L., Trigg, J., \& Hogg, R. S. (2020). Physical distancing in COVID-19 may exacerbate experiences of social isolation among people living with HIV. AIDS and Behavior, 24(22), 2250 2252. https://doi.org/10.1007/s10461-020-02872-8

Morin, A. (2020, August 25). How collective trauma impacts your health. https://www.verywellmind.com/effects-of-collective-trauma-5071346

Moss, V. (2020). Addressing collective trauma: Building capacity for rural leaders and service providers: Lecture 2 [PowerPoint slides]. Collaborative Solutions. https://csi.elevate.commpartners.com/p/addtrauma1

Nanton, C. R. (2009). Ties that bind: Culturally referent groups and coping strategies of adult women learners. New Directions for Adult and Continuing Education, 122, 13-22.

Nydegger, L. A., Dickerson-Gomez, J., \& Ko Ko, T. (2020). Structural and syndemic barriers to PrEP adoptions among Black women at high risk for HIV: A qualitative exploration. Culture, Health \& Sexuality. https://doi.org/10.1080/13691058.2020.1720297

Onos, J. (2020, September 30. Race and medicine: The cost of medical bias when you're sick, Black, and female. https://www.healthline.com/health/the-costof-medical-bias-when-youre-sick-black-and-female

Opara, I. (2017). Examining African American parent-daughter HIV risk communication using a Black feminist-ecological lens: Implications for intervention. Journal of Black Studies, 49(2), 134-151. https://doi.org/10.1177/0021934717741900

Operario, D., King, E. J., \& Gamarel, K. E. (2020). Prioritizing community partners and community HIV workers in the COVID-19 pandemic. AIDS and Behavior, 24(1), 2748-2750. https://doi.org/10.1007/s10461-020-02896-0

Pinto, R. M., \& Park, S. (2020). COVID-19 pandemic disrupts HIV continuum of care and prevention: Implications for research and practice concerning community-based organizations and frontline providers. AIDS and Behavior, 24(9), 2486-2489. https://doi.org/10.1007/s10461-020-02893-3 
Rao, D., Andrasik, M. P., \& Lipira, L. (2018). HIV stigma among Black women in the United States: Intersectionality, support, resilience. American Journal of Public Health, 108(4), 446-448. https://doi.org/10.2105/ajph.2018.304310

Riley, D. E., Ghandi, M., Hare, C., Cohen, J., \& Hwang, S. (2007). Poverty, unstable housing, and HIV infection, among women living in the United States. Current HIV/AIDS Reports, 4(4), 181-186. https://doi.org/10.1007/s11904007-0026-5

Sangaramoorthy, T., Jamison, A., \& Dyer, T. (2017). Intersectional stigma among midlife and older Black women living with HIV. Culture, Health \& Sexuality, $\quad$ 19(12), https://doi.org/10.1080/13691058.2017.1312530

1329-1343.

Weaver, T. L., Gilbert, L., El-Bassel, N., Resnick, H. S., \& Noursi, S. (2015). Identifying and intervening with substance-using women exposed to intimate partner violence: Phenomenology, comorbidities, and integrated approaches within primary care and other agency settings. Journal of Women's Health, 24(1), 51-56. https://doi.org/10.1089/jwh.2014.4866

Whiteside, Y. O., Cohen, S. M., Bradley, H., Skarbinski, J., Hall, I., \& Lansky, A. (2014). Progress along the continuum of HIV care among Blacks with diagnosed HIV-United States, 2010. Morbidity and Mortality Weekly Report, 63(35), 85-89.

Wilson, M. G., Lavis, N. J., \& Guta, A. (2012). Community based organizations in the health sector: A scoping review. Health Research Policy and Systems, 10, Article 36. http://www.health-policy-systems.com/content/10/1/36

Mattyna Stephens, Ph.D., is a Regional Health Care Planner for Brazos Valley Council of Governments. She teaches graduate-level courses at Texas A\&M University. Her research streams include (1) Black grandmothers caring for their grandchildren in rural communities, (2) impact of the coronavirus on HIV/AIDS efforts for BWLHA, and (3) Black women aging with HIV/AIDS. Email: stephensmattyna@gmail.com.

Gwenetta Curry, Ph.D., is a Lecturer of Race, Ethnicity, and Health at the University of Edinburgh. Her research interests include: (1) racial and ethnic health disparities, (2) Black family studies, and (3) Black male studies. Email: gwenetta.curry@ed.ac.uk.

Stacey Stephens, MSW, LCSW-C, is a Clinical Instructor at the University of Maryland School of Social Work and an Adjunct Professor at Morgan State University School of Social Work. Her primary research interests include (1) the health and well-being of vulnerable women, (2) children and families, (3) maternal and child health, (4) achieving health equity, and (5) community engagement. Email: sstephens@ssw.umaryland.edu. 